\title{
PROPOSTA DE NIVELAMENTO EM ATENDIMENTO ÀS NOVAS DIRETRIZES CURRICULARES NACIONAIS PARA CURSOS DE ENGENHARIA: CONSTRUÇÃO DE UM ESPECTROFOTÔMETRO COMO APRENDIZAGEM POR
} PROJETO

\author{
LEVELING PROPOSAL IN COMPLIANCE WITH THE NEW NATIONAL CURRICULUM GUIDELINES \\ FOR ENGINEERING COURSES: CONSTRUCTION OF A SPECTROPHOTOMETER AS LEARNING \\ BY PROJECT \\ João Lucas Melo de Oliveira ${ }^{1}$, Alexandre Saron ${ }^{2}$ \\ DOI: 10.37702/REE2236-0158.v39p450-462.2020
}

\section{RESUMO}

A Resolução 02 de 24 de abril de 2019 do Conselho Nacional do Ensino Superior estabeleceu as novas Diretrizes Curriculares Nacionais de graduação em Engenharia. Em atendimento aos capítulos III e IV, foi desenvolvida uma proposta de atividade técnico-científica com integração da teoria à prática, que visa ao acolhimento e nivelamento de alunos ingressantes com conteúdos básicos do curso de Engenharia, contemplando a interdisciplinaridade e utilizando laboratórios de Física, Química e Informática. Com o uso de metodologias ativas, especificamente a Aprendizagem por Projeto, ocorreu, neste projeto, o desenvolvimento de um protótipo de baixo custo, um espectrofotômetro, e o relato da possibilidade de integração dos conteúdos básicos presentes em qualquer habilitação de Engenharia. O processo avaliativo deverá ser adaptado pela Instituição de Ensino em questão, ou seja, provas dissertativas, apresentações orais, artigos técnicos entre outros, desde que demonstrem o aprendizado e estimulem a produção intelectual dos estudantes, de forma individual ou em equipe.

Palavras-chave: Projeto integrador; espectrofotômetro; Engenharia; Novas Diretrizes Curriculares Nacionais.

\begin{abstract}
Resolution 02 of April 24, 2019 of the National Council of Higher Education established the new National Curriculum Guidelines for engineering graduation. In compliance with chapters III and IV, a proposal of technical-scientific activity was developed with integration of theory to practice that aims to host and level students entering with basic contents of the engineering course contemplating interdisciplinarity using physics, chemistry and informatics laboratories. With the use of active methodologies, Learning by Project, there was the development of a low-cost prototype, a spectrophotometer and the report of the possibility of integrating the basic contents present in any engineering qualification in this project. The evaluation process should be adapted by the Educational Institution in question, i.e., dissertation tests, oral presentations, technical articles, among others, as long as they demonstrate learning and stimulate the intellectual production of students, individually or as a team.
\end{abstract}

Keywords: Integrating project, Spectrophotometer, Engineering, New National Curriculum Guidelines.

\footnotetext{
${ }^{1}$ Graduando em Engenharia Ambiental e Sanitária, Centro Universitário Senac, Aluno bolsista PIBIC - CNPq; joao_lucasmo@ @otmail.com

${ }^{2}$ Doutor em Ensino de Ciências e Matemática, Centro Universitário Senac, Professor e pesquisador, alexandre.saron@sp.senac.br
} 


\section{INTRODUÇÃO}

Um dos principais desafios educacionais contemporâneos é fazer com que o aluno enxergue como o conteúdo aprendido em sala de aula se aplica aos problemas e desafios do mercado de trabalho, no mundo real. Muitos estudantes questionam a utilidade dos conhecimentos adquiridos em sala de aula e isso faz com que esses conhecimentos que são essenciais para atuação profissional - mesmo que os estudantes não percebam isso - não sejam aprendidos de fato, apenas decorados para "passar" nas provas. No que tange às questões das metodologias ativas, sobre como formar melhores engenheiros e como inovar a sala de aula, é essencial trabalhar com projetos de engenharia que englobem diversas disciplinas e conceitos passados em sala de aula como uma estratégia de fixar o conhecimento e para que os alunos sintam que as aulas frequentadas realmente têm uma importância prática e um sentido (ELMÔR et al., 2019).

A área da Engenharia, que é de importância para o desenvolvimento tecnológico e econômico do país, exige cada vez mais o conhecimento técnico, isto é, saber fazer. Por isso, a adoção de metodologias ativas nos cursos de Engenharia se apresenta como um grande potencial enquanto ferramenta para o processo de aprendizagem, uma vez que o aluno passa a poder visualizar a teoria da sala de aula na prática e isso permite que ele tenha autonomia na construção do conhecimento, tendo o professor $\mathrm{o}$ papel de orientador $\mathrm{e}$ mediador.

A adoção do uso de metodologias ativas no ensino é essencial para mudar o cenário da educação que vem se formando nos últimos anos: falta de interesse dos alunos, comprometimento da aprendizagem e distanciamento dos alunos, configurados por métodos tradicionais e ultrapassados que ainda são utilizados por muitos professores (MACHADO et al., 2017).

Baseando-se no trabalho realizado por Saron (2016), que considerou o estilo de aprendizagem dos estudantes ingressantes de um curso de Engenharia para a elaboração de uma Unidade de Ensino Direcionada e Potencialmente Significativa - UEDPS, o objetivo deste trabalho foi desenvolver uma proposta de aprendizagem interdisciplinar direcionada para alunos ingressantes de cursos de habilitação em Engenharia, através da metodologia ativa denominada Aprendizagem por Projeto, cujo desafio de engenharia para o desenvolvimento do processo de ensinoaprendizagem foi a construção de um equipamento real denominado espectrofotômetro. A Espectroscopia é a ciência que estuda interações de radiações de luz com a matéria, e a espectrofotometria realiza a quantificação.

Neste trabalho, os autores construíram o espectrofotômetro, que foi alvo de pesquisa de Iniciação Científica em um curso de Engenharia Ambiental e Sanitária. Havia como premissa a obtenção de um protótipo de baixo custo e que apresentasse boa reprodutibilidade estatística dos resultados em amostras para a quantificação da concentração de azul de metileno em solução.

A metodologia neste artigo, para a proposta de Aprendizagem por Projeto, visou à interdisciplinaridade dos seguintes conteúdos básicos descritos no Art. $9^{\circ} \S 1$ da Resolução 02/2019 que instituiu as novas Diretrizes Curriculares Nacionais (DCNs) do curso de Graduação em Engenharia: Algoritmos e Programação; Eletricidade; Estatística. Expressão Gráfica; Física; Informática; Matemática; Metodologia Científica e Tecnológica; e Química. Ainda, levou-se em consideração o $\S 3$, o qual solicita a utilização de práticas e de laboratório, inclusive para os conteúdos básicos, com enfoque e intensidade compatíveis com a habilitação da Engenharia, sendo indispensáveis essas atividades nos casos de Física, Química e Informática (BRASIL, 2019). A proposta metodológica apresentada neste trabalho está direcionada ao primeiro ano dos cursos de Engenharia como ferramenta de nivelamento descrito no artigo $7^{\circ}$ da Resolução 02 de 2019 e propicia uma formação técnica nas competências do aluno (BRASIL, 2019).

Assim, o presente trabalho apresenta importante desenvolvimento metodológico, 
aplicável como proposta de nivelamento para cursos de Engenharia e que poderá ser implementada nos Projetos Pedagógicos de Cursos (PPC) de Instituições de Ensino Superior (IES) em atendimento às novas DCNs, com possibilidade de adaptações no projeto alvo, o espectrofotômetro, mas contendo os conceitos de formação básica de cursos de Engenharia solicitados nas novas DCNs para a promoção de acolhimento e nivelamento do aluno ingressante.

\section{METODOLOGIAS ATIVAS E A APRENDIZAGEM POR PROJETO}

Moran (2018) define metodologias ativas como "estratégias de ensino centradas na participação efetiva dos estudantes na construção do processo de aprendizagem, de forma flexível, interligada e híbrida" (MORAN, 2018, p. 4). O ser humano aprende quando outro mais experiente fala e explica, mas também quando há envolvimento direto com experimentação, perguntas, projetos, atividades e pesquisas. $\mathrm{Na}$ educação as metodologias dedutivas são predominantes. Isso é, primeiro o professor explica a teoria e transmite o conhecimento e depois o aluno deve aplicar esse conhecimento em situações mais específicas, como resolução de problemas, experimentos e projetos. De acordo com o autor "as metodologias ativas dão ênfase ao papel protagonista do aluno, ao seu envolvimento direto, participativo e reflexivo em todas as etapas do processo, experimentando, desenhando, criando, com orientação do professor [...]" (MORAN, 2018, p. 4).

O que se pode observar é que a transmissão do conhecimento e da teoria do professor para o aluno é importante, porém, esse não deve ser o único método de aprendizagem, pois se o aluno não aplica esse conhecimento, ele não aprende de verdade, e, então, o conhecimento não é fixado. Além disso, o aluno fica com um sentimento de que o que ele aprendeu não faz sentido algum, pois ele não vivenciou nenhuma experiência ou atividade que mostre a aplicação do conhecimento transmitido pelo professor. Ainda segundo Moran (2018, p. 4), “a aprendizagem mais profunda requer espaços de prática frequentes (aprender fazendo) [...] Por isso, é importante o estímulo multissensorial e a valorização dos conhecimentos prévios dos estudantes para 'ancorar' os novos conhecimentos".

Nesse contexto, existem diversas metodologias ativas consolidadas que podem ser aplicadas. Entre as mais difundidas podem ser citadas como exemplos a Problem Based Learning (PBL), sala de aula invertida, situação-problema, estudo de caso, ensino híbrido, gamificação e Aprendizagem por Projeto. Saron (2016) direcionou a metodologia ativa a ser desenvolvida em sala de aula por meio do conhecimento do estilo de aprendizagem dos estudantes, possibilitando promover uma educação mais centrada no aluno.

Aprendizagem por Projeto, segundo Moran (2018):

É uma metodologia de aprendizagem em que os alunos se envolvem com tarefas e desafios para resolver um problema ou desenvolver um projeto que também tenha ligação com sua vida fora da sala de aula. No processo, eles lidam com questões interdisciplinares, tomam decisões e agem sozinhos e em equipe. Por meio dos projetos, são trabalhadas também suas habilidades de pensamento crítico, criativo e a percepção de que existem várias maneiras para a realização de uma tarefa, tidas como competências necessárias para o século XXI (MORAN, 2018, p. 10).

De acordo com Moran (2018), os projetos que se apresentam como efetivos possuem os seguintes atributos: reconhecem o impulso intrínseco dos alunos para aprender; envolvem os alunos nos conceitos e princípios centrais de uma disciplina; destacam questões provocativas; requerem a utilização de ferramentas e habilidades essenciais, incluindo tecnologia para aprendizagem, autogestão e gestão do projeto; especificam produtos que resolvem problemas; incluem múltiplos produtos que permitem feedback; utilizam avaliações baseadas em desempenho; estimulam alguma forma de cooperação.

$\mathrm{O}$ autor realiza também a classificação de diferentes formas de Aprendizagens por Projetos como proposta de metodologia ativa 
de ensino-aprendizagem, sendo elas: a) exercício projeto - quando o projeto é aplicado no âmbito de uma única disciplina; b) componente projeto - quando o projeto é desenvolvido de modo independente das disciplinas, apresentando-se como uma atividade acadêmica não articulada com nenhuma disciplina específica; c) abordagem projeto - quando o projeto se apresenta como uma atividade interdisciplinar, ou seja, como elo entre duas ou mais disciplinas; d) currículo projeto - quando não mais é possível identificar uma estrutura formada por disciplinas, pois todas elas se dissolvem e seus conteúdos passam a estar a serviço do projeto e vice-versa; e) projeto construtivo - a finalidade é construir algo novo, criativo, no processo e/ou no resultado; f) projeto investigativo - o foco é pesquisar uma questão ou situação, utilizando técnicas de pesquisa científica; g) projeto explicativo - procura responder questões do tipo: "Como funciona? Para que serve? Como foi construído?", busca explicar, ilustrar e revelar os princípios científicos de funcionamento de objetos, mecanismos, sistemas etc. Moran (2018) ainda comenta que os projetos podem ser desenvolvidos dentro de cada disciplina; de forma integrada entre diversas disciplinas e de forma transdisciplinar.

Nesse contexto, Projeto Integrador é uma disciplina na qual os alunos têm a oportunidade de colocar em prática conhecimentos adquiridos durante o semestre, de forma integrada e por meio de projetos reais. A classificação do Projeto Integrador, segundo Moran (2018), depende do objetivo e da estruturação do projeto, podendo estar dentro de uma ou mais classificações. Durante o semestre é desenvolvido um projeto prático em equipe, com foco nos conteúdos estudados durante o semestre e aplicação da metodologia de pesquisa. Essa disciplina é um diferencial na formação, pois possibilita o aluno a ter contato com situações reais do dia a dia do profissional. Mas, além de tudo, é uma disciplina que visa também a consolidar conhecimentos fundamentais à formação do aluno de Engenharia como indicado pelas Novas DCNs (SENAC, 2015; BRASIL, 2019).

\section{APRENDIZAGEM POR PROJETO E O PROJETO INTEGRADOR NA IMPLEMENTAÇÃO DAS NOVAS DCNS DOS CURSOS DE ENGENHARIA}

As novas Diretrizes Curriculares Nacionais para os cursos de Engenharia entraram em vigor pela Resolução no 2 de 24 de abril de 2019. Essas novas DCNs foram reformuladas dentro de um contexto no qual se buscou, principalmente, elevar a qualidade dos cursos priorizando a construção de competências (habilidades + atitudes + conhecimento) -, oferecer aos alunos atividades compatíveis com as demandas do mercado, formar engenheiros que não são apenas técnicos, mas também inovadores e empreendedores, e reduzir a evasão dos cursos de Engenharia. Considerando esse cenário, as Novas DCNs buscam contribuir para o alinhamento entre a formação de engenheiros no Brasil e os novos paradigmas tecnológicos, econômicos e sociais. Um dos pontos de atenção indicados é o protagonismo do aluno, que deve estar presente ao longo de todo o currículo (CNI, 2020).

Dentro desse contexto de protagonismo do aluno, os projetos integradores perfazem potenciais ferramentas para o processo de ensino-aprendizagem com foco na autonomia do aluno na construção do conhecimento e poderão servir para oferecer o acolhimento e nivelamento do aluno ingressante nos cursos de Engenharias (MORAN, 2018; SARON, 2013; BRASIL, 2019). Em relatório síntese da Comissão Nacional para Implantação das Novas Diretrizes Curriculares Nacionais do Curso de Graduação em Engenharia (CNDCNs) são apontados como parte das estratégias do processo formativo programas de acolhimento, nivelamento e acompanhamento.

Nesse sentido, os projetos integradores se apresentam também como potenciais ferramentas educacionais para acolhimento e nivelamento de conhecimentos básicos de engenharia dos alunos recém-chegados do ensino médio e acompanhamento destes, podendo assim serem diagnosticados pontos 
fortes, fracos, dificuldades, entre outras observações de interesse pedagógico ao longo de seu desenvolvimento (SANTOS; BARRA, 2012; MORAN, 2018; SARON; AMARAL, 2016; BRASIL, 2019).

A proposta metodológica a ser apresentada também cumpre com o exposto nos parágrafos do Artigo $6^{\circ}$ da referida Resolução, o qual enfatiza a obrigatoriedade do uso de laboratórios de Física, Química e Informática; o uso de metodologias ativas centradas no protagonismo do aluno; a importância de atividades que articulem simultaneamente a teoria, a prática e o contexto de aplicação, necessárias para o desenvolvimento das competências estabelecidas no perfil do egresso; a importância de atividades que promovam a integração e a interdisciplinaridade, de modo coerente com o eixo de desenvolvimento curricular e de forma a nivelar os conhecimentos técnicos e científicos para continuidade no curso de Engenharia.

Em conformidade com o Artigo $8^{\circ}$, a proposta é elaborada de forma a ser aplicada como uma disciplina (que poderá ser denominada niveladora ou Projeto Integrado), na qual serão trabalhadas diversas disciplinas apontadas no Artigo $9^{\circ}$ como básicas e obrigatórias para os cursos de Engenharia independente da habilitação específica. Dessa forma, é aplicável tanto a cursos semestrais, trimestrais ou quadrimestrais, em que há ingresso de alunos em diferentes épocas do ano, dependendo do modelo adotado pela Instituição de Ensino.

\section{ESPECTROFOTÔMETRO COMO PROJETO DE APRENDIZAGEM: FUNCIONAMENTO E APLICAÇÃO DO CONHECIMENTO}

A interação tanto da luz visível e da luz não visível (ultravioleta e infravermelho) com a matéria possibilitou o desenvolvimento de técnicas analíticas qualitativas e quantitativas de substâncias denominadas analitos. Uma dessas técnicas é a espectrofotometria, ou colorimetria. Essa técnica consiste em incidir um feixe de luz sobre uma amostra, medir a quantidade de luz que foi absorvida $\mathrm{e}$ transmitida e, utilizando modelos matemáticos, relacionar a quantidade de luz absorvida com a concentração do analito na amostra. Em um espectrofotômetro de feixe único, um feixe de luz branca passa por um dispositivo monocromador (filtro, prisma, grade de difração, etc.), incide sobre a cubeta contendo a amostra, e um fotodetector realiza a leitura da luz transmitida. Nesse tipo de aparelho há a necessidade de realizar uma referência, que se é obtida fazendo a leitura apenas com o solvente (HIGSON, 2009). A Figura 1 apresenta o funcionamento de um espectrofotômetro de feixe único.

\section{Figura 1 - Funcionamento de um espectrofotômetro de feixe único}

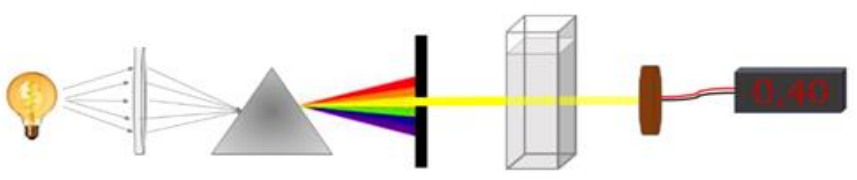

Fonte: Rosa et al., 2019.

Para compreensão do funcionamento de um espectrofotômetro que opera na região visível do espectro eletromagnético é necessário entender o comportamento da luz branca, sua decomposição e a relação entre cores absorvidas e transmitidas (complementares). A Figura 2 apresenta a relação entre luz absorvida e cor observada. Esta relação é importante para a escolha do comprimento de onda a ser utilizado na análise de um determinado composto que forme complexo colorido quando em solução aquosa. 


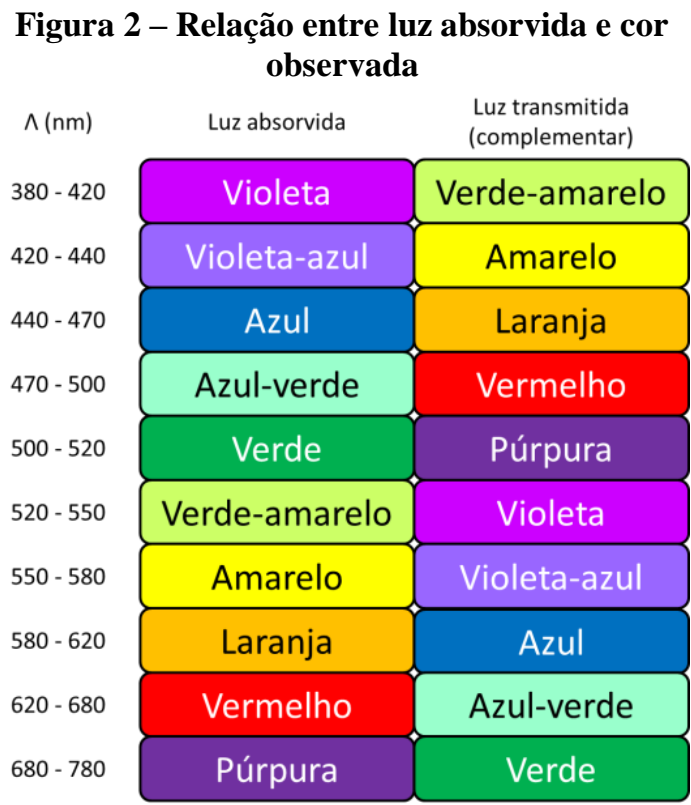

Fonte: adaptada de Coutrim, 2014.

Nessa relação, uma solução colorida contida em uma cubeta transparente absorve o comprimento de onda complementar à cor por esta transmitida. Em um espectrofotômetro, uma parte da luz que incide na cubeta com a amostra e percorre o seu caminho ótico é absorvida. Isso indica que a luz incidente $\left(\mathrm{I}_{0}\right)$ tem uma intensidade maior de energia do que a luz que emerge (I) da cubeta (HIGSON, 2009). A Figura 3 ilustra um feixe de luz passando por uma amostra contida em uma cubeta transparente cuja composição preferencial é de quartzo, mas há no mercado também as de vidro e de plástico que poderão absorver parcela de luz, ocasionando erros analíticos.

Figura 3 - Absorção de luz da amostra contida em uma cubeta

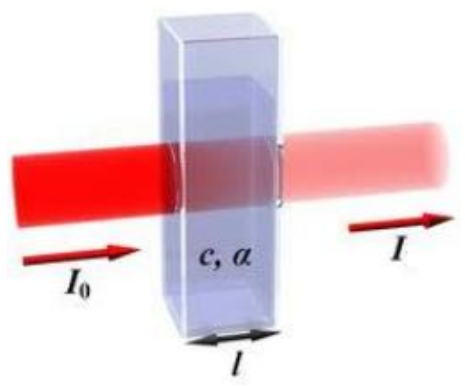

Fonte: Coutrim, 2014.

De acordo com Skoog et al. (2014), a lei da absorção, conhecida como Lei de BeerLambert, relaciona a absorção à concentração, ao comprimento do trajeto e à absortividade molar de acordo com a Equação (1):

$$
A=\log \frac{I_{0}}{I}=\varepsilon C_{n} l
$$

em que: $\varepsilon$ é absortividade molar, também conhecido como coeficiente de extinção ( $\mathrm{L} \mathrm{mg}^{-}$ ${ }^{1} \mathrm{~cm}^{-1}$ ); Cn é concentração do analito ( $\mathrm{mol} \mathrm{L}^{-1}$ ou mg L $\mathrm{m}^{-1}$ ); 1 é o comprimento do trajeto, ou seja, da cubeta que contém o analito $(\mathrm{cm})$.

Uma solução que se apresenta com cor púrpura $(680-780 \mathrm{~nm})$ absorve a cor verde $(500-520 \mathrm{~nm})$. Vários autores trabalharam com soluções aquosas de permanganato de potássio $\left(\mathrm{KMnO}_{4}\right)$. Trata-se de uma substância química cuja presença em solução aquosa transmite a cor púrpura ou violeta em baixas concentrações (TAVENER; THOMASOATES, 2007; MOREIRA; SANTOS; COSTA, 2016). De acordo com a Figura 2, o comprimento de onda ideal para realizar as análises de absortividade dessa substância está entre $500 \mathrm{~nm}$ e $550 \mathrm{~nm}$, que é o comprimento de onda da cor verde ou amarelo-verde, sendo esta a faixa de cor complementar à da solução.

Para que possa ser quantificada uma determinada substância deve ser elaborada uma curva de calibração. Trata-se de uma função matemática de primeiro grau. Este gráfico é resultado da absorbância (A) da luz em função da concentração do analito em um determinado comprimento de onda de maior absorção. O coeficiente angular é o produto da absortividade molar $\varepsilon$ da substância e do caminho ótico da cubeta utilizada. A Figura 4 apresenta a curva de calibração para o permanganato de potássio em meio neutro a comprimento de onda de $525 \mathrm{~nm}$. 
Figura 4 - Curva de calibração para permanganato de potássio em meio neutro a 525 nm

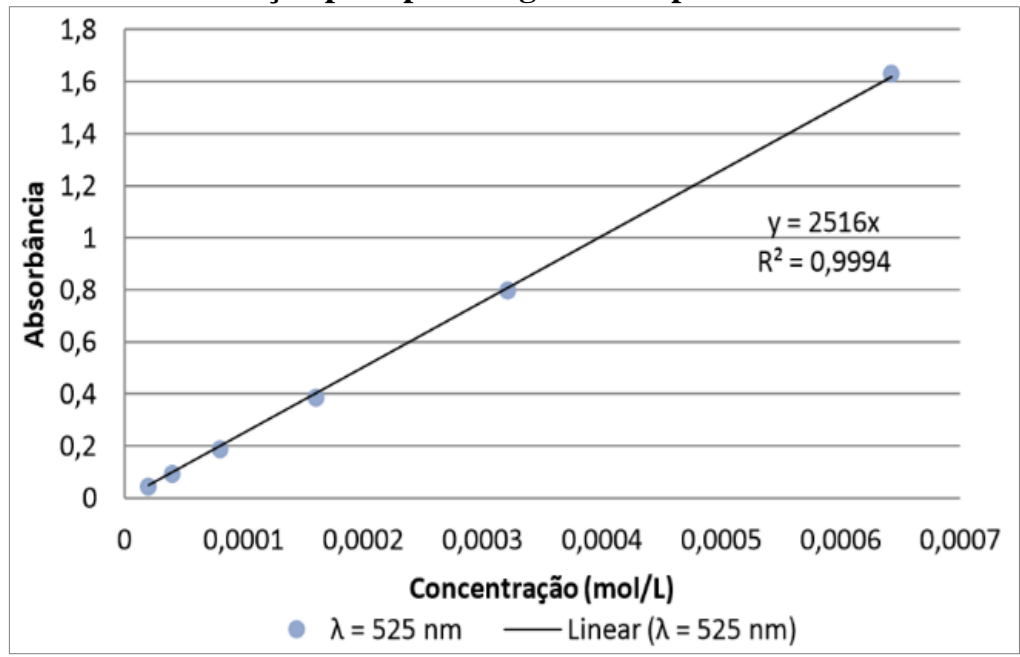

Fonte: Toute e Theodoro, 2014.

$\mathrm{Na}$ construção de um espectrofotômetro como um protótipo de um projeto de engenharia existem diversas aplicações de conhecimentos de disciplinas do ciclo básico, servindo também como nivelamento para os alunos ingressantes dos cursos. O Quadro 1 apresenta os tópicos mínimos de abordagem no contexto de cada disciplina a ser trabalhado como modalidade de nivelamento em um primeiro ano de um curso de Engenharia.

Quadro 1 - Tópicos mínimos de abordagem no contexto das disciplinas integradas no projeto

\begin{tabular}{|l|l|}
\hline Disciplina & Tópicos mínimos de abordagem \\
\hline $\begin{array}{l}\text { Física } \\
\text { Eletricidade e e }\end{array}$ & $\begin{array}{l}\text { Conceitos básicos de óptica; } \\
\text { Circuitos elétricos, componentes } \\
\text { eletrônicos e conceitos de elétrica. }\end{array}$ \\
\hline Matemática & $\begin{array}{l}\text { Operações básicas; } \\
\text { Representação gráfica de funções }\end{array}$ \\
\hline $\begin{array}{l}\text { Química Geral e } \\
\text { Experimental }\end{array}$ & $\begin{array}{l}\text { Concentrações e preparo de soluções } \\
\text { químicas; } \\
\text { Boas práticas de laboratório. }\end{array}$ \\
\hline $\begin{array}{l}\text { Algoritmos } \\
\text { Programação }\end{array}$ & $\begin{array}{l}\text { Lógica; } \\
\text { Desenvolvimento de algoritmos; } \\
\text { Introdução a projetos com Arduino. }\end{array}$ \\
\hline $\begin{array}{l}\text { Expressão } \\
\text { Gráfica }\end{array}$ & $\begin{array}{l}\text { Preparo de desenhos para corte em } \\
\text { máquina laser CNC; } \\
\text { Introdução a softwares de desenho } \\
\text { auxiliado por computador. }\end{array}$ \\
\hline $\begin{array}{l}\text { Metodologia } \\
\text { Científica } \\
\text { Tecnológica }\end{array}$ & $\begin{array}{l}\text { etodologia científica; } \\
\text { Pesquisa e investigação científica; } \\
\text { Redação de relatórios e artigos técnico- } \\
\text { científicos. }\end{array}$ \\
\hline Estatística & $\begin{array}{l}\text { Regressão linear; } \\
\text { Gráficos de dispersão; } \\
\text { Ferramentas do Excel; } \\
\text { Erro relativo. }\end{array}$ \\
\hline
\end{tabular}

Fonte: elaborado pelos autores.

\section{PROPOSTA METODOLÓGICA PARA UM PROJETO INTEGRADOR TENDO COMO OBJETIVO A CONSTRUÇÃO DE UM ESPECTROFOTÔMETRO}

A seguir será apresentada uma proposta metodológica como um roteiro para a construção de um espectrofotômetro com a finalidade de integração e nivelamento de disciplinas do conteúdo básico de qualquer habilitação de Engenharia. Sugere-se que seja seguida tal proposta, porém o professor poderá realizar alterações conforme achar necessário para melhor desenvolvimento dos alunos na Instituição de Ensino, bem como deve ter o papel de mediador ao longo do processo. Caso decida-se seguir a proposta dos autores serão necessários os materiais: caixa de MDF com tampa e fecho $(24,5 \times 9,5 \times 8,5 \mathrm{~cm})$; filtro de absorção laranja (52 mm de diâmetro); sensor LDR (Light Dependant Resistor); LED branco difuso $5 \mathrm{~mm}$; fios do tipo jumper; Arduino UNO R3; Protoboard 400 furos; resistores de $62 \Omega$ e $10 \mathrm{~K} \Omega$; e cubeta confeccionada em vidro óptico de $1 \mathrm{~cm}$. O custo total do projeto foi de $\mathrm{R} \$ 166,29$.

Para a construção do espectrofotômetro devem ser desenhadas em AutoCAD, e cortadas em máquina a laser CNC, três peças em MDF de $3 \mathrm{~mm}$ de espessura que têm a função de afunilar a luz do LED, isolar resíduos de luz 
branca para que não interfira na leitura e para servir de suporte para os filtros e para a cubeta. Essas peças devem possuir as dimensões de largura e altura de modo que se encaixem justamente na caixa de MDF e devem possuir um furo de $5 \mathrm{~mm}$ no centro. Nessa etapa são trabalhados os conhecimentos relacionados à disciplina de Expressão Gráfica.

O LED deve ser ligado em série com o resistor de $62 \Omega$ para que possa operar sem queimar com a tensão de $5 \mathrm{~V}$ da placa Arduino. $\mathrm{O}$ resistor de $10 \mathrm{~K} \Omega$ deve ser ligado em série com o LDR, formando um divisor de tensão, para aumentar a sensibilidade do LDR, uma vez que este possui uma resistência muito alta no escuro e uma resistência muito baixa quando a luz incide sobre o mesmo. Os fios devem ser encaixados na Protoboard de forma a ligar os componentes do circuito. Uma ponta do fio azul deve ser ligada ao LDR e a outra ponta encaixada na entrada analógica A0 da placa Arduino. Este esquema tem como função medir a tensão que passa pelo LDR, possibilitando realizar as leituras necessárias. A Figura 5 mostra o aparelho montado.

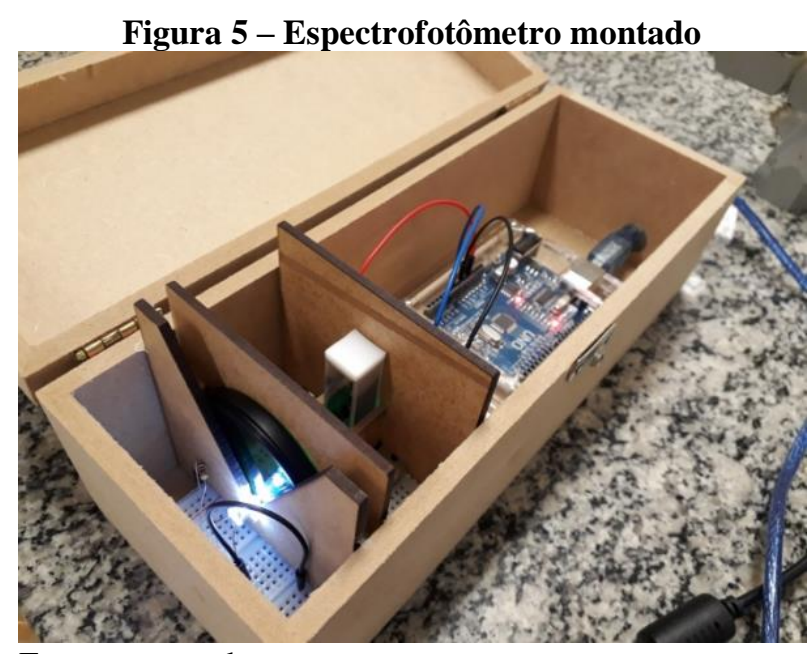

Fonte: acervo dos autores.

A Figura 6 apresenta o circuito elétrico do aparelho finalizado de acordo com a proposta metodológica apresentada, alvo de estudo em conteúdos das disciplinas de Física e Eletricidade.
Figura 6 - Circuito elétrico do aparelho finalizado

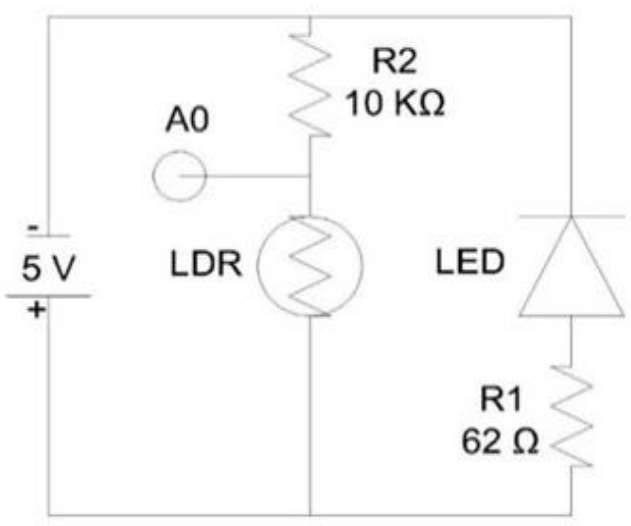

Fonte: elaborada pelos autores.

O código a ser utilizado para este trabalho (Figura 7) tem como função imprimir no serial plotter da IDE do Arduino os valores lidos no sensor LDR e, ao mesmo tempo, calcular a média móvel dos valores para reduzir as incertezas causadas por oscilações e ruídos nas leituras, intrínsecas a esse tipo de medição. Nessa etapa são trabalhados os conhecimentos da disciplina de Algoritmos e Programação com uso de Laboratório de Informática.

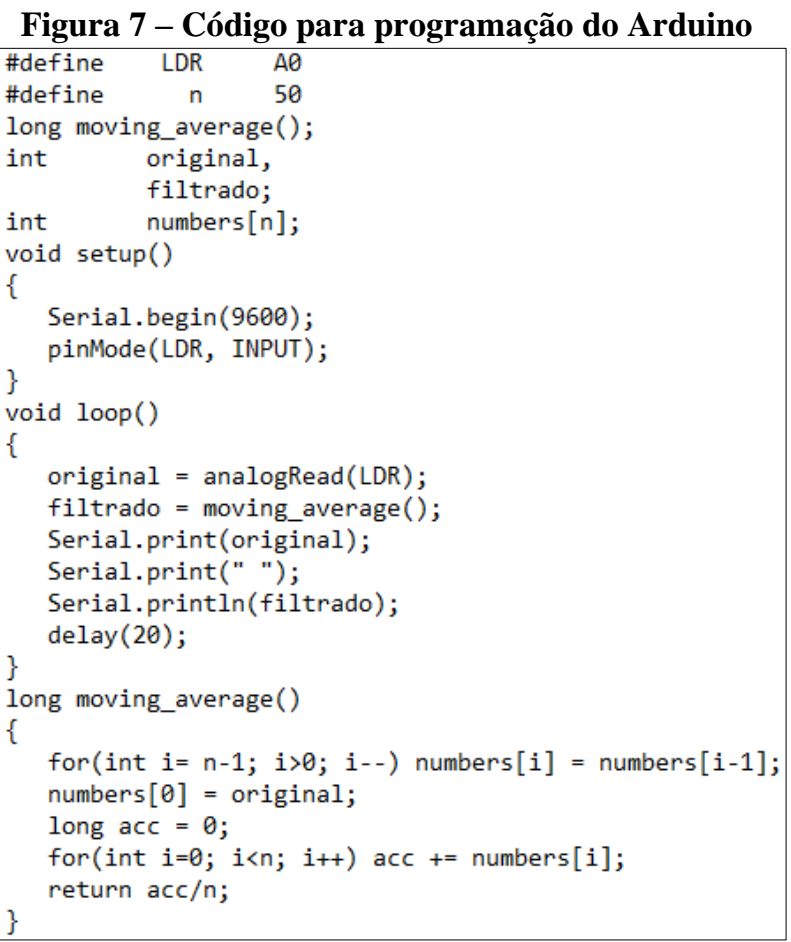

Fonte: adaptada de Rambo, 2017. 
Os valores lidos no serial plotter da IDE do Arduino estarão expressos em uma resolução de 10 bits (1024 unidades) da placa, ou seja, é possível realizar leituras entre $0 \mathrm{~V}$ e $5 \mathrm{~V}$ sendo expressas em um intervalo de 0 a 1023 unidades. Fazendo a divisão de 5V por 1024 unidades temos aproximadamente $0,004883 \mathrm{~V}$ por unidade de leitura. Logo, para efetuar a conversão dos valores lidos no serial plotter da IDE do Arduino o valor deve ser multiplicado por $0,004883 \mathrm{~V}$.

Segundo Tavener e Thomas-Oates (2007), para aplicar os valores em Volts na Lei de BeerLambert deve-se também tirar uma medida do ruído de fundo, isto é, realizar uma leitura sem luz incidindo sobre o sensor LDR, o qual é o detector. Subtrair o valor obtido de todas as leituras realizadas para o ajuste sem o ruído de fundo. Logo, tem-se as seguintes relações matemáticas para construção da curva de calibração de acordo com a Equação (2):

$$
A=\log \frac{V_{\text {branco }}-V_{\text {ruído de fundo }}}{V_{\text {analito }}-V_{\text {ruído de fundo }}}=\varepsilon C_{n} l
$$

Para realização de ensaios a fim de verificar a eficiência do aparelho deve ser elaborada uma curva de calibração utilizando a substância Azul de metileno $\left(\mathrm{C}_{16} \mathrm{H}_{18} \mathrm{~N}_{3} \mathrm{SCl}\right)$. Essa substância é recomendada, pois permite comparações com trabalhos publicados em diversos artigos científicos de acesso em internet e bases eletrônicas de pesquisas. Para essa curva de calibração deve ser utilizado um filtro de absorção laranja cujo comprimento de onda range em $580 \mathrm{~nm}$ a $620 \mathrm{~nm}$ (COUTRIM, 2014). As concentrações das soluções padrões utilizadas para a elaboração da curva podem ser de 2, 4, 6, 8 e $10 \mathrm{mg} / \mathrm{L}$. Deve ser utilizada uma cubeta confeccionada em vidro óptico com caminho óptico de $1 \mathrm{~cm}$ e água destilada como solvente das soluções. Para minimizar erros e variações nos resultados a cubeta deve ser utilizada sempre com a mesma face virada para o feixe de luz. A curva pode ser elaborada com a média de três leituras realizadas para o branco (apenas água destilada), o ruído de fundo e as concentrações, ou mais repetições, fica a critério do professor. Após a elaboração da curva de calibração podem ser realizados testes com soluções-problema em diferentes concentrações para determinar o erro relativo e a precisão do aparelho desenvolvido.

A Figura 8 apresenta a curva de calibração obtida para o azul de metileno, tangenciando estudos que podem ser conduzidos em disciplinas de Química Geral e Experimental, Matemática e Estatística.

Figura 8 - Curva de calibração obtida para o azul de metileno

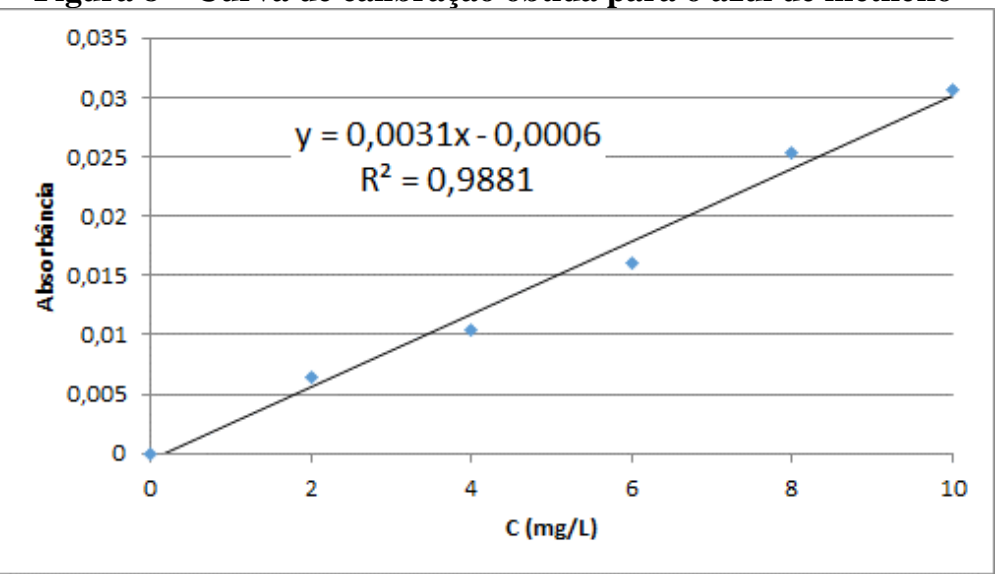

Fonte: elaborada pelos autores.

A Tabela 1 apresenta os resultados dos testes de validação no espectrofotômetro realizados para o azul de metileno e o valor dos erros relativos. $\mathrm{O}$ tratamento de dados primários obtidos experimentalmente poderão ser alvos de discussão na disciplina de Estatística. 
Tabela 1 - Resultados dos testes de validação para o azul de metileno

\begin{tabular}{c|c|c}
\hline Concentração real (mg/L) & $\begin{array}{c}\text { Concentração obtida com a curva } \\
\text { de calibração }(\mathbf{m g} / \mathbf{L})\end{array}$ & Erro relativo $(\%)$ \\
\hline 1 & 1,03 & 3,0 \\
5 & 4,12 & 17,6 \\
7 & 6,20 & 11,4 \\
\hline
\end{tabular}

Fonte: elaborada pelos autores.

Apesar de obtida uma boa linearidade para a curva de calibração no espectrofotômetro construído como ensaio desta proposta metodológica de Aprendizagem por Projeto para ser aplicada como nivelamento de conhecimentos em um curso de Engenharia, os valores de absorbância estão muito baixos em relação ao que é indicado por Higson (2009), para o qual os valores obtidos devem estar entre 0,1 e 2. Por outro lado, em Skoog, et al. (2014) também são indicados valores de absorbância abaixo de 0,1 e acima de 2 . Isso pode ser explicado pelo fato de o sensor LDR utilizado como detector responder de modo diferente de outros sensores, como fototransístor, fotodiodo ou tubos fotomultiplicadores. Em muitos trabalhos é possível encontrar valores de absorbância semelhantes, como, por exemplo, em Tavener e Thomas-Oates (2007), Moreira, Santos e Costa (2016) e Rosa et al. (2019). Esses valores não significam que a curva está errada, mas sim que cada sensor responde de forma diferente.

Quanto aos testes de validação foi obtido um erro relativo médio de $10,6 \%$. Apesar de o coeficiente de correlação da curva de calibração ser 0,9881 , o aparelho em funcionamento na prática apresentou uma precisão de cerca de $90 \%$. Um valor alto considerando que os componentes utilizados em sua confecção são de baixo custo. Apesar de não apresentar qualidade analítica de aparelhos comerciais (>99\%), conhecer toda a engenharia que está dentro de um equipamento e conhecer sua aplicação prática perfaz uma potencial ferramenta para um processo de ensinoaprendizagem. Ainda é válido ressaltar que os resultados obtidos introduzem o aluno à percepção de que nem sempre os modelos físicos e matemáticos representam com exatidão a realidade, inferindo na aprendizagem do aluno sob o contexto de saber interpretar com isenção e pensamentos críticos resultados obtidos de testes e experimentos, utilizando-se das ferramentas matemáticas, estatísticas e tecnológicas para a sistematização e análise dos dados obtidos.

\section{RESULTADOS E DISCUSSÕES}

Na metodologia é possível afirmar que são cumpridos os requisitos necessários para que uma metodologia ativa de aprendizagem por experimentação, problematização ou projeto, seja eficaz e, conforme comenta Pinheiro (1996), potencialmente ensinável, ou seja, pelo menos teoricamente, possa ser aprendida pelo aluno a que se destina. Para o atendimento desse requisito são levadas em consideração a faixa etária dos alunos, a especificidade do curso e da disciplina escolar dos quais farão parte; e possibilitar a elaboração de objetivos de ensino, de exercícios, avaliações ou trabalhos práticos.

O desenvolvimento da proposição de projeto integrador apresentado possui potencial como ferramenta educacional de acolhimento, nivelamento e acompanhamento. Possui os atributos de uma aprendizagem por projeto conforme é afirmado por Moran (2018), e se encaixa nas categorias de Abordagem projeto, Projeto construtivo, explicativo e integrador. Isso pode ser verificado a partir dos conhecimentos utilizados no projeto desenvolvido, que provêm de disciplinas do ciclo básico dos cursos de Engenharia.

A proposta metodológica de projeto integrador aqui apresentada também se traduz em uma potencial atividade desenvolvedora de competências e habilidades demandadas pela sociedade e pelo mercado, uma vez que além do produto principal, o aparelho espectrofotômetro, também são trabalhados 
outros conhecimentos importantes para a indústria, por exemplo, conceitos básicos e fundamentais de óptica, presente em diversas aplicações industriais, tecnológicas e corriqueiras (SANTOS; BARRA, 2012; MION et al., 2017).

A proposta metodológica de projeto integrador apresentada está diretamente relacionada ao perfil e às competências esperadas do egresso de cursos de Engenharia segundo o Artigo $4^{\circ}$ da Resolução 02 de 24 de abril de 2019 que institui as Novas DCNs. Essas competências gerais são: formular e conceber soluções desejáveis de engenharia, analisando e compreendendo os usuários dessas soluções e seu contexto; analisar e compreender os fenômenos físicos e químicos por meio de modelos simbólicos, físicos e outros, verificados e validados por experimentação; conceber, projetar e analisar sistemas, produtos (bens e serviços), componentes ou processos; implantar, supervisionar e controlar as soluções de engenharia; comunicar-se eficazmente nas formas escrita, oral e gráfica; trabalhar e liderar equipes multidisciplinares; conhecer e aplicar com ética a legislação e os atos normativos no âmbito do exercício da profissão e aprender de forma autônoma a lidar com situações e contextos complexos, atualizando-se em relação aos avanços da ciência, da tecnologia e aos desafios da inovação (BRASIL, 2019).

\section{CONSIDERAÇÕES FINAIS}

O espectrofotômetro é um aparelho que possui inúmeras aplicações analíticas de quantificações, seja de bancada, em processo ou até mesmo em campo. Um aluno egresso de um curso de Engenharia - que poderá ser o usuário do equipamento, ou não - deve conhecer seu princípio de funcionamento além da sua simples utilização. Isso requer conhecimentos de diferentes áreas como a Química, a Física, Design, entre outras, bem como deixa clara sua interação com a Pesquisa, Tecnologia e as demandas do mercado e da sociedade.

O desenvolvimento de um espectrofotômetro como proposta de metodologia ativa de ensino-aprendizagem para cursos de Engenharia possui potencial de trabalho para ser aplicado como projeto de integração de disciplinas do ciclo básico dos cursos de Engenharia, sendo também uma potencial ferramenta educacional para acolhimento, nivelamento e acompanhamento de alunos ingressantes para qualquer modalidade de Engenharia.

A metodologia proposta possui o potencial de cumprir a missão de demonstração e aplicação para os alunos de graduação. Ademais, apresentou resultados com boa precisão, de baixo custo operacional e elaboração simplificada, permitindo a replicação desta metodologia ativa de aprendizagem por projeto, sempre inserindo melhorias contínuas advindas das percepções dos docentes durante o desenvolvimento do trabalho no decorrer do período de aplicação, o qual se sugere que seja no primeiro ou segundo semestre do curso de Engenharia, independente da habilitação. Além dos conteúdos descritos neste artigo, outros desenvolvimentos metodológicos de conhecimentos da área de engenharias poderão ser inseridos na proposta de trabalho, por exemplo pela criação de banco de dados, transmissão de informações via wireless como proposta de introdução à Internet das Coisas, entre outros.

\section{REFERÊNCIAS}

BRASIL. MEC/CNE/CES. Resolução no 2 de 24 de abril de 2019. Disponível em: http://www.in.gov.br/web/dou//resolu\%C3\%87\%C3\%83o-n\%C2\%BA-2-de24-de-abril-de-2019-85344528 Acesso em: 01 jul. 2020.

CNI - CONFEDERAÇÃO NACIONAL DA INDÚSTRIA. Comissão Nacional para Implantação das Novas Diretrizes Curriculares Nacionais do curso de Graduação em Engenharia (CD-DCNs): relatório síntese. 2020. Disponível em: abenge.org.br Acesso em: 20 jun. 2020.

COUTRIM, M. X. QUI 346 Espectrofotometria. 2014.

Disponível em: 
https://docplayer.com.br/15795488-Qui346espectrofotometria.html Acesso em: 28 jun. 2020.

ELMÔR, G. et. al. Uma nova sala de aula é possível: aprendizagem ativa na educação em engenharia. $1^{\text {a }}$ ed. Rio de Janeiro: LTC, 2019.

HIGSON, S. Química analítica. São Paulo: McGraw-Hill, 2009.

MACHADO, A. B. et. al. Práticas inovadoras em metodologias ativas. Florianópolis: Contexto Digital, 2017.

MION, J. A. et. al. A óptica aplicada na indústria: um enfoque da sua importância nos cursos de Engenharia. Revista Acadêmica, São Paulo, v. 1, n. 19, p. 213-233, jan./jun., 2017.

MORAN, J. Metodologias ativas para uma aprendizagem mais profunda. In: $\mathrm{BACICH}, \mathrm{L}$; MORAN, J. (Orgs.). Metodologias ativas para uma educação inovadora: uma abordagem teórico-prática. Porto Alegre: Penso, 2018.

MOREIRA, A. F.; SANTOS, S. R. B.; COSTA, A. G. Construção e caracterização de um fotômetro destinado ao uso de aulas experimentais de química sobre a Lei de BeerLambert. In: HOLOS, vol. 2, p. 142-151, 2016.

PINHEIRO, T. F. Aproximação entre a ciência do aluno na sala de aula da $1^{\circ}$ série do $2^{\circ}$ grau e a ciência dos cientistas: uma discussão. 1996. Dissertação (Mestrado) - Universidade Federal de Santa Catarina, Santa Catarina, 1996.

RAMBO, W. Filtro de média móvel e serial plotter: Curso de Arduino \#108. 2017. Disponível em: https://www.youtube.com/watch?v=cxPQ0A MQ5bo Acesso em: 07 mar. 2020.

ROSA, C. L. et. al. Construção de espectrofotômetro para fins didáticos. Journal of Exact Sciences - JES, v. 21, n. 1, p. 20-25, abr./jun., 2019.

SANTOS, M. C. C.; BARRA, S. R. O projeto integrador como ferramenta de construção de habilidades e competências no ensino de engenharia e tecnologia. Anais... XL Congresso Brasileiro de Educação em Engenharia (COBENGE). Belém, 2012.

SARON, A. Estudantes universitários gostam de cerveja? Um relato de experiência de aprendizagem baseada em problema para a Engenharia Ambiental. Anais... XLI Congresso Brasileiro de Educação em Engenharia (COBENGE). Gramado, 2013.

SARON, A. Unidade de ensino direcionada e potencialmente significativa no ensino de Química Ambiental: uma experiência sobre aprendizagem de índice de qualidade de água considerando estilos de aprendizagem. 2016. Tese (Doutorado) - Programa de PósGraduação em Ensino de Ciências e Matemática da Universidade Cruzeiro do Sul, São Paulo, 2016.

SARON, A.; AMARAL, C. L. C. O ensino de Química em curso de Engenharia Ambiental Estudo de caso no Centro Universitário Senac. Boletim Técnico Senac, Rio de Janeiro, v. 42 n. 1, p. 48-69, jan./abr., 2016.

SENAC. Projeto Integrador. Rio de Janeiro: Coleção de documentos técnicos do modelo pedagógico Senac, 2015.

SKOOG, D. et. al. Fundamentos de química analítica. $9^{a}$ ed. São Paulo: Cengage Learning, 2014.

TAVENER, S. J.; THOMAS-OATES, J. E. Build your own spectrophotometer. Education in Chemistry, sep. 2007, p. 151-154, 2017.

TOUTE, P. A.; THEODORO, T. P. Caracterização do escoamento com reação fotoquímica simultânea de permanganato de potássio em solução aquosa. 2014. Trabalho de Conclusão de Curso (POLIUSP), São Paulo, 2014. 


\title{
DADOS BIOGRÁFICOS DOS AUTORES
}
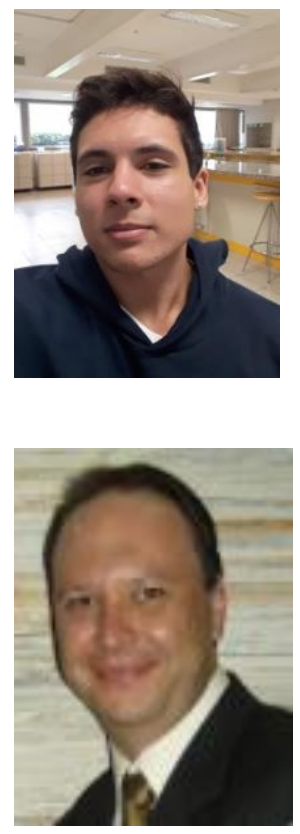

João Lucas Melo de Oliveira - Graduando em Engenharia Ambiental e Sanitária pelo Centro Universitário Senac (2018). Monitor da disciplina de Química Geral e Experimental para as engenharias e aluno de Iniciação Cientifica bolsista do CNPq sob orientação do Prof. Dr. Alexandre Saron. Participou do XLVII COBENGE (Congresso Brasileiro de Educação em Engenharia) e do $59^{\circ}$ Congresso Brasileiro de Química, recebendo Menção Honrosa na XXXII Jornada de Iniciação Científica em Química.

\begin{abstract}
Alexandre Saron - Engenheiro Químico pela Faculdade Oswaldo Cruz (1994), Mestre em Engenharia Civil pela UNICAMP (2000), Especialista em Docência do Ensino Superior (2000), Especialista em Engenharia de Segurança do Trabalho (2006) e Doutor em Ensino de Ciências e Matemática pela Universidade Cruzeiro do Sul (2016). Atualmente é professor do Centro Universitário Senac, cuja atuação docente está nos cursos de graduação em Engenharia Ambiental e Sanitária, Engenharia da Produção e Engenharia da Computação. Atuação docente na graduação com as disciplinas de Química Geral e Experimental, Química Ambiental, Engenharia de Segurança do Trabalho e Projetos de Engenharia. Na pósgraduação Lato sensu com disciplinas de Química Ambiental, Tratamento de água, Tratamento de efluentes. Possui alunos de monitoria e iniciação científica.
\end{abstract}

